\title{
Suplementos para ovinos mantidos em pastos de capim-marandu
}

\author{
Daniel Marino Guedes de Carvalho(1), Luciano da Silva Cabral(1), Joanis Tilemahos Zervoudakis ${ }^{(1)}$, \\ Thiago Luiz Queiroz Arnoldo(1), João Marcos Beltrame Benatti ${ }^{(1)}$, Jefferson Fabiano Werner Koscheck ${ }^{(1)}$, \\ Maurício Nobuyuki Miyashita Piona ${ }^{(1)}$ e André Alves de Oliveira ${ }^{(1)}$
}

(1)Universidade Federal de Mato Grosso, Faculdade de Agronomia, Medicina Veterinária e Zootecnia, Avenida Fernando Correia da Costa, no 2.367, Boa Esperança, CEP 78060-900 Cuiabá, MT. E-mail: danielguedes14@yahoo.com.br, cabralls@ufmt.br, joanisz@yahoo.com.br, thiagoarnoldo@hotmail.com, jonizoo@hotmail.com, jeffersonfwk@hotmail.com, mauriciopiona@hotmail.com, andrezoo07@yahoo.com.br

\begin{abstract}
Resumo - O objetivo deste trabalho foi avaliar o efeito da suplementação na resposta produtiva, no $\mathrm{pH}$ e no nitrogênio amoniacal ruminal, e no custo de produção de ovinos em pastagem de capim-marandu no período da seca. $O$ experimento teve a duração de 84 dias. Utilizaram-se 20 cordeiros não castrados com idade e peso corporal inicial médios de quatro meses e $24,20 \mathrm{~kg}$, respectivamente, para avaliação do desenvolvimento, distribuídos em cada um dos tratamentos que são os suplementos, mineral, energético, proteico e múltiplo, com cinco animais por tatamento, em área de 0,1 ha. Para avaliação dos parâmetros nutricionais, foram utilizados quatro ovinos fistulados no rúmen com 12 meses e $55 \mathrm{~kg}$ de peso corporal foram distribuídos em quatro piquetes de 0,1 ha. Avaliaram-se os suplementos mineral, energético, múltiplo e proteico. Os ganhos de peso foram de $0,017,-0,008,0,024$ e $0,077 \mathrm{~kg}$ por dia para os suplementos mineral, energético, múltiplo e proteico, respectivamente. Quatro horas após suplementação, os valores de $\mathrm{pH}$ ruminal foram de 6,30, 6,40, 6,18 e 6,24 para os suplementos mineral, energético, múltiplo e proteico, respectivamente. Os valores para nitrogênio amoniacal do líquido ruminal foram de $10,57,7,36,21,58$ e $24,50 \mathrm{mg} \mathrm{dL}^{-1}$ para os suplementos mineral, energético, múltiplo e proteico, respectivamente. Os suplementos mineral e proteico produziram o ganho de peso com o menor custo. $\mathrm{O}$ uso de suplemento energético para cordeiros submetidos à forragem com baixo teor de proteína reduz o ganho de peso.
\end{abstract}

Termos para indexação: capim-braquiária, ganho de peso, parâmetros ruminais, proteína, rentabilidade, suplementação.

\section{Supplements for sheep maintained on marandu grass pastures}

\begin{abstract}
The objective of this work was to evaluate the effect of supplementation on the productive response, ruminal $\mathrm{pH}$ and ammoniacal nitrogen, and production cost of sheep grazing marandu grass in the dry season. The experiment lasted 84 days. Twenty noncastrated lambs with average age and initial body weight of four months and $24.2 \mathrm{~kg}$, respectively, were used for performance evaluation, and were distributed in the following treatments which are, mineral salt, energetic, multiple and proteic supplements, with five animals per treatment, in area of 0.1 ha. For nutritional parameters evaluation, four rumen fitted sheep with 12 months of age and $55 \mathrm{~kg}$ of weight were distributed in four paddocks of 0.1 ha. Mineral salt, energetic, multiple and proteic supplements were evaluated. Weight gains were $0.017,-0.008,0.024$ and $0.077 \mathrm{~kg}$ per day for mineral salt, energetic, proteic and multiple supplements, respectively. Four hours after supplementation, ruminal $\mathrm{pH}$ values were 6.30, 6.40, 6.18 and 6.24 for mineral salt, energetic, multiple and proteic supplements, respectively. Values for ammoniacal nitrogen in the rumen fluid were $10.57,7.36,21.58$ and $24.50 \mathrm{mg} \mathrm{dL}^{-1}$ for mineral salt, energetic, multiple and proteic supplements, respectively. Mineral salt and proteic supplements produced weight gain with the lowest cost. The use of energetic supplement for lambs grazing lower protein content forage reduces weight gain.
\end{abstract}

Index terms: palisade grass, weight gain, ruminal parameters, protein, profitability, supplementation.

\section{Introdução}

O processo de globalização tem causado grandes mudanças em diversos setores do agronegócio brasileiro. Na ovinocultura, tem-se buscado caminhos para o estabelecimento de sistemas de produção capazes de produzir, de forma eficiente, carne de boa qualidade a baixo custo. No entanto, a produtividade desses animais nos trópicos ainda é baixa, principalmente em razão da distribuição estacional e da variação qualitativa e quantitativa da forragem (Mallmann et al., 2006).

As limitações nutricionais associadas à sazonalidade da produção e do valor nutritivo das forrageiras necessitam de correção, no sentido de permitir o aumento do desempenho e do lucro nesses sistemas de produção. A suplementação de ovinos em pastejo

Pesq. agropec. bras., Brasília, v.46, n.2, p.196-204, fev. 2011 
é necessária quando nutrientes não são fornecidos pela forragem basal em balanço e não há quantidade adequada para atender os requisitos do animal nem as metas de desempenho previamente estabelecidas (Cavalcanti Filho et al., 2004).

Para que a ovinocultura possa se tornar competitiva em relação aos outros segmentos do agronegócio, é preciso ser eficiente do ponto de vista biológico e produzir carne com qualidade e menor custo (Silva et al., 2009). A suplementação de ovinos em pastejo no período da seca tem se destacado como uma alternativa para melhorar o desempenho animal; porém, questionamentos sobre o custo da suplementação têm sido levantados por produtores quanto à adoção da tecnologia. O tipo de suplemento empregado, seu nível de fornecimento e composição, bem como os ganhos proporcionados devem ser considerados no momento da sua implementação em sistemas de produção com base no uso de forrageiras, para a maior eficiência do sistema e a maximização da renda do produtor rural (Carvalho et al., 2009).

Moraes et al. (2010) destacam que a redução dos custos de produção depende não apenas do menor custo de alimentação, mas também de estruturas mais simples relacionadas ao transporte e à distribuição dos suplementos. Assim, a utilização de suplementos do tipo autocontrole de consumo pode ser uma alternativa de manejo de suplementos em sistemas de produção de ruminantes em pastejo.

No período da seca, a proteína tem sido considerada o nutriente mais limitante ao desempenho dos animais em pastejo, notadamente aqueles submetidos às gramíneas tropicais. O fornecimento deste nutriente via suplemento torna-se fundamental para reduzir a perda ou aumentar o ganho de peso. Segundo Van Soest (1994), o fornecimento de fontes de nitrogênio $(\mathrm{N})$ ou energia pode ter efeitos diferenciados, dependendo da concentração de $\mathrm{N}$ da dieta e das exigências do animal em relação ao requisito da microbiota ruminal. Em dietas com baixo teor de proteína bruta (PB), como as de animais mantidos em capins tropicais na seca, o requisito da microbiota ruminal é superior ao do animal, e o uso de suplementos com proteína degradável no rúmen (PDR) é desejável, enquanto o uso de fontes de energia de rápida fermentação é indesejável. De acordo com o autor, o uso de carboidratos de rápida fermentação ruminal, tais como o amido, em dietas deficientes em PDR pode ser prejudicial, pois tende a reduzir a disponibilidade de compostos nitrogenados aos microrganismos que utilizam os carboidratos fibrosos.

Em estudos in vitro (Costa et al., 2008) ou com animais fistulados (Souza et al., 2010), há efeito negativo da suplementação com amido sobre a digestão da fibra da forragem de baixa qualidade. Entretanto, na prática, há controvérsias, o que permite que alguns técnicos e produtores em condições de campo utilizem suplementos para animais de forma indiscriminada, sem a avaliação da composição da forragem disponível e do tipo de suplemento.

O objetivo deste trabalho foi avaliar o efeito da suplementação na resposta produtiva, no $\mathrm{pH}$ e no nitrogênio amoniacal ruminal, e no custo de produção de ovinos em pastagem de capim-marandu no período da seca.

\section{Material e Métodos}

O experimento foi conduzido no setor de ovinocultura da fazenda experimental da Universidade Federal de Mato Grosso (UFMT), localizada no Município de Santo Antônio de Leverger, MT, na região da Baixada Cuiabana, de 27 de julho a 18 de outubro de 2008, com duração de 84 dias. As coordenadas geográficas do local do experimento são $15^{\circ} 51^{\prime} \mathrm{S}, 56^{\circ} 04^{\prime} \mathrm{W}$, a $141 \mathrm{~m}$ de altitude. O clima da região é do tipo $\mathrm{Cwa}$, segundo a classificação de Köepen, tropical, sazonal, com duas estações bem definidas: verão chuvoso (outubro a março) e inverno seco (abril a setembro).

Para a avaliação do desempenho, os animais foram distribuídos em quatro piquetes de 0,1 ha cada um, formados com a gramínea Urochloa brizantha cv. Marandu, providos de bebedouros e cochos cobertos. Os dados meteorológicos do período experimental e dos dois meses que antecederam ao início do experimento (Tabela 1) foram obtidos na estação meteorológica da UFMT.

Tabela 1. Precipitação mensal $(\mathrm{mm})$ e temperaturas $\left({ }^{\circ} \mathrm{C}\right)$ máximas, mínimas e médias mensais, durante o período experimental.

\begin{tabular}{lcccc}
\hline Mês & $\begin{array}{c}\text { Precipitação } \\
\text { mensal }\end{array}$ & $\begin{array}{c}\text { Temperatura } \\
\text { máxima }\end{array}$ & $\begin{array}{c}\text { Temperatura } \\
\text { mínima }\end{array}$ & $\begin{array}{c}\text { Temperatura } \\
\text { média }\end{array}$ \\
\hline Junho & - & 33,60 & 10,90 & 22,25 \\
Julho & - & 36,80 & 11,70 & 24,25 \\
Agosto & 12,50 & 39,30 & 14,00 & 26,65 \\
Setembro & 23,30 & 40,50 & 13,20 & 26,85 \\
Outubro & 82,40 & 41,80 & 18,10 & 29,95 \\
\hline
\end{tabular}

Fonte: Estação meteorológica da fazenda experimental da UFMT. 
Foram utilizados 20 cordeiros não castrados, deslanados sem raça definida, com idade e peso corporal médio inicial de quatro meses e $24,2 \mathrm{~kg}$, respectivamente, distribuídos aleatoriamente nos tratamentos (suplementos): MM, mistura mineral (testemunha); SE, mistura mineral, sal comum $(\mathrm{NaCl})$ e milho grão moído; SM, mistura mineral, ureia/ sulfato de amônio (9:1), sal comum $(\mathrm{NaCl})$, milho grão moído e farelo de soja; SP, mistura mineral, ureia/ sulfato de amônio (9:1), sal comum $(\mathrm{NaCl})$ e farelo de soja. Os animais foram pesados no início e no final do experimento sem jejum prévio, e a cada 28 dias para monitoramento do desempenho a cada período experimental. Foi realizada a rotação dos animais entre os piquetes a cada 14 dias, para reduzir possíveis variações entre a disponibilidade e a qualidade da forragem nos piquetes experimentais. Todos os animais foram submetidos ao controle de ecto e endoparasitos no início e no meio do experimento, com produto à base de closantel; o critério para realizar a vermifugação foi a quantidade de ovos por grama de fezes, abaixo de 500 .

Além dos animais usados para medir o desempenho, foi alocado, em cada um dos piquetes, um animal canulado no rúmen para a avaliação do $\mathrm{pH}$ e das quantidades de nitrogênio amoniacal $\left(\mathrm{N}-\mathrm{NH}_{3}\right)$ ruminal. Os procedimentos utilizados com os animais foram aprovados pelo comitê de ética da Pró-Reitoria de Pesquisa da UFMT. Os animais canulados foram alocados em delineamento quadrado latino $4 \times 4$, e cada período experimental correspondeu a 14 dias. Do primeiro ao décimo terceiro dia experimental, os animais foram adaptados aos suplementos. A coleta de líquido ruminal para a determinação do $\mathrm{pH}$ e do $\mathrm{N}-\mathrm{NH}_{3}$ foi realizada no décimo quarto dia. O líquido ruminal foi coletado nos tempos zero hora (antes do fornecimento do suplemento) e quatro horas (quatro horas após o fornecimento do suplemento), próximo à abertura da cânula ruminal, e filtrado em um béquer com auxílio de duas peneiras de porosidade $2 \mathrm{~mm}$ sobrepostas uma a outra. A leitura do $\mathrm{pH}$ foi realizada com um peagâmetro digital imediatamente após a coleta do material. Depois da leitura do $\mathrm{pH}$, uma alíquota de $50 \mathrm{~mL}$ foi acondicionada em recipiente de plástico com $1 \mathrm{~mL}$ de ácido sulfúrico $\left(\mathrm{H}_{2} \mathrm{SO}_{4}\right)$ 1:1 e congelada a $-20^{\circ} \mathrm{C}$, para posteriores análises das concentrações de $\mathrm{N}-\mathrm{NH}_{3}$.
A composição percentual dos suplementos com base na matéria natural encontra-se na Tabela 2 . Os suplementos foram fornecidos na quantidade de $0,105 \mathrm{~kg}$ por animal, diariamente às $10 \mathrm{~h}$, a fim de manter a oferta de suplemento em proporção de $0,4 \%$ do peso corporal (PC). As possíveis sobras foram monitoradas diariamente, para evitar o desperdício com os suplementos.

No primeiro dia de cada período experimental, realizou-se a coleta de amostras da forragem nos diferentes piquetes por meio do corte, a $5 \mathrm{~cm}$ do solo, de dez áreas delimitadas por um quadrado metálico de $0,5 \times 0,5 \mathrm{~m}$, escolhidas aleatoriamente em cada piquete experimental, para estimar a massa de forragem $\left(\mathrm{kg} \mathrm{ha}^{-1}\right)$.

Após a coleta, as amostras de cada piquete foram pesadas e homogeneizadas, e, em seguida, retiraramse duas alíquotas compostas: uma para avaliação da disponibilidade total de massa de forragem $\left(\mathrm{kg} \mathrm{ha}^{-1}\right)$ e outra para análise das disponibilidades de massa de matéria seca por hectare de folha verde, folha seca, colmo verde e colmo seco. A avaliação da forragem ingerida pelos animais foi realizada com a técnica da simulação manual de pastejo, pela coleta de amostras de pasto em duas linhas diagonais em cada piquete, no primeiro dia de cada período experimental; procurouse manter os mesmos amostradores, para diminuir a variabilidade dos resultados.

Todo o material coletado foi imediatamente congelado em freezer a $-20^{\circ} \mathrm{C}$ para posterior análise de laboratório. Também foram feitas amostragens dos ingredientes usados para a formulação do suplemento e dos suplementos depois de misturados.

As amostras dos ingredientes, dos suplementos e da forragem foram analisadas no laboratório de nutrição animal da UFMT quanto às variáveis massa de matéria

Tabela 2. Custo dos ingredientes $(\mathrm{R} \$$ por $\mathrm{Mg}$ ) e composição percentual dos suplementos na matéria natural.

\begin{tabular}{|c|c|c|c|c|c|}
\hline \multirow[t]{2}{*}{ Ingrediente } & \multirow[t]{2}{*}{ Custo $^{(2)}$} & \multicolumn{4}{|c|}{$\begin{array}{c}\text { Composição dos suplementos } \\
(\%)^{(3)}\end{array}$} \\
\hline & & MM & SE & SM & SP \\
\hline Farelo de soja & 720,00 & - & - & 20,00 & 55,00 \\
\hline Milho grão moído & 500,00 & - & 60,00 & 35,00 & - \\
\hline Ureia + sulfato de amônio $(9: 1)$ & $1.200,00$ & - & - & 5,00 & 5,00 \\
\hline Mistura mineral $^{(1)}$ & $1.875,00$ & 100,00 & 30,00 & 30,00 & 30,00 \\
\hline Sal comum $(\mathrm{NaCl})$ & 200,00 & - & 10,00 & 10,00 & 10,00 \\
\hline
\end{tabular}


seca (MS), matéria orgânica (MO), proteína bruta (PB), matéria mineral (MM), fibra em detergente neutro (FDN), fibra em detergente ácido (FDA) e hemicelulose (HEM), realizadas de acordo com as técnicas descritas por Silva \& Queiroz (2002).

Para a avaliação econômica, o valor atribuído à megagrama de cada ingrediente foi obtido por cotação de preço no mercado local em três fornecedores diferentes. O custo dos suplementos foi calculado em razão do nível de inclusão de cada ingrediente multiplicado pelo seu respectivo preço por unidade de produto $(\mathrm{kg})$. O custo por dia $(\mathrm{R} \$)$ foi calculado pela multiplicação do consumo de suplemento animal por dia pelo preço por quilograma de suplemento. A margem bruta por quilograma de ganho foi calculada pela diferença entre o valor pago por quilograma de produto e o custo total com suplemento, para que o animal produzisse este quilograma de ganho.

Para calcular o custo da mão de obra, assumiu-se a contratação de um funcionário com capacidade para cuidar de 500 animais com remuneração mensal de $\mathrm{R} \$ 545,00$. Foram considerados os mesmos custos com mão de obra para os suplementos energético, múltiplo, proteico e mistura mineral, pois os suplementos usados foram de autocontrole de consumo, com a mesma frequência de reabastecimento dos cochos para os tratamentos, apesar de experimentalmente, o fornecimento de todos os suplementos ter sido efetuado diariamente.

Os dados de desempenho animal foram analisados considerando-se o delineamento inteiramente casualizado, segundo o modelo estatístico:

$$
\mathrm{y}_{\mathrm{ij}}=\mu+\mathrm{t}_{\mathrm{i}}+\mathrm{e}_{\mathrm{ij}} \text {, }
$$

em que: $\mu$, é a constante geral; $\mathrm{t}_{\mathrm{i}}$, é o efeito do suplemento $\mathrm{i}\left(\mathrm{i}=1,2,3\right.$ e 4); $\mathrm{e}_{\mathrm{ij}}$, é o erro aleatório, associado à cada observação, pressuposto $\operatorname{NID}\left(0, \sigma^{2}\right)$.

Os dados de $\mathrm{pH}$ e $\mathrm{N}-\mathrm{NH}_{3}$ foram analisados tendose considerado o quadrado latino, segundo o modelo estatístico:

$$
\mathrm{y}_{\mathrm{ijk}}=\mu+\mathrm{Si}+\mathrm{Aj}+\mathrm{Pk}+\mathrm{eijk}
$$

em que: $\mu$, é a constante geral; $\mathrm{Si}$, é o efeito do suplemento i ( $\mathrm{i}=1,2,3$ e 4$) ; \mathrm{Aj}$, é o efeito referente ao animal $\mathrm{j}(\mathrm{j}=1,2,3$ e 4); $\mathrm{Pk}$, é o efeito referente ao período experimental $\mathrm{k}(\mathrm{k}=1,2,3$ e 4$)$; e e $\mathrm{e}_{\mathrm{ijk}}$, é o erro aleatório, associado à cada observação, pressuposto $\operatorname{NID}\left(0, \sigma^{2}\right)$.
Os dados foram analisados por meio de análise de variância, e o teste de Student-Newman-Keulls foi adotado para as comparações entre médias. Todas as análises foram realizadas pelo programa Saeg da Universidade Federal de Viçosa (SAEG, 1995), a 5\% de probabilidade.

\section{Resultados e Discussão}

Foram observados valores médios de massa de forragem total (MSFT) de lâminas foliares verdes (MSLV), lâminas foliares mortas (MSLM), colmos verdes (MSCV) e colmos mortos (MSCM) na pastagem de 4.140, 630, 650, 1.460 e $1.400 \mathrm{~kg} \mathrm{ha}^{-1}$, respectivamente (Figura 1).

O comportamento dos dados de disponibilidade está de acordo com os observados por Carvalho et al. (2009), em pastagem de U. brizantha cv. Marandu. Os baixos valores encontrados para as variáveis MSLV e MSLM, em setembro e outubro, são reflexo da baixa taxa de crescimento das forrageiras no período da seca, somado à grande capacidade seletiva dos ovinos, que consomem preferencialmente lâmina foliar verde em vez de colmos, por ser uma dieta mais adequada às suas exigências nutricionais.

Apesar de a massa de forragem estar acima do limite mínimo de $2.000 \mathrm{~kg} \mathrm{ha}^{-1}$ sugerido por Minson (1990), como valor abaixo do qual o consumo pode ser limitado, ela apresentava elevada proporção de colmos e reduzida proporção de laminas foliares verdes.

Em sistemas de produção animal a pasto, o consumo é influenciado pela disponibilidade. Assim, os valores para MSFT contribuíram para o desempenho alcançado pelos animais. Segundo Euclides et al. (2000), no caso

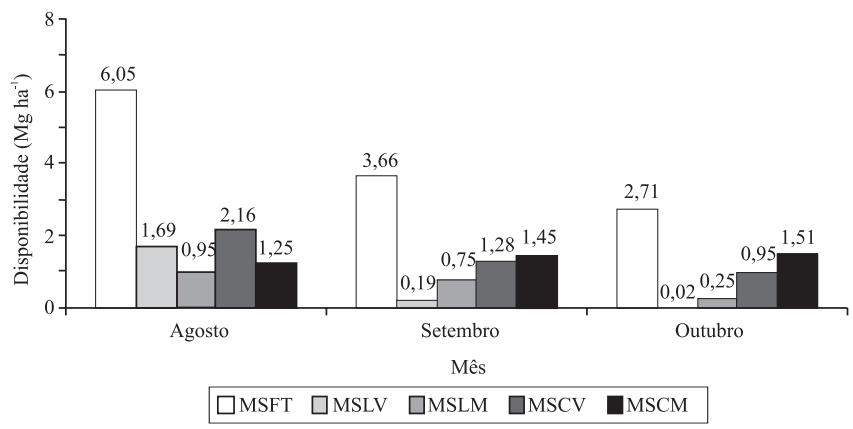

Figura 1. Disponibildiade de massa de forragem total (MSFT), de lâminas foliares verdes (MSLV), lâminas foliares mortas (MSLM), colmos verdes (MSCV) e colmos mortos (MSCM) de capim-marandu, em cada período experimental. 
de pastagens tropicais, em que há grande acúmulo de material morto, a pressão de pastejo deve ser expressa em massa de forragem verde, especialmente como lâminas foliares verdes. Não há relação entre o desempenho animal e a produção por hectare quando a pressão de pastejo é calculada com base na massa de matéria seca total de forragem (MST), mas, ao ser calculada com massa de matéria seca verde (MSV), é positiva; o animal tende a selecionar apenas folhas verdes e a recusar folhas secas e colmos.

Quanto aos valores referentes à composição químico-bromatológica da forragem pastejada pelos animais no período experimental (Tabela 3), foram observados valores médios de $4,78 \%$ de $\mathrm{PB}$, valor superior aos encontrados por Paulino et al. (2002) e Gomes Júnior et al. (2002) de 2,52 e 3,96\% de PB, respectivamente. Por outro lado, esse valor é mais próximo dos valores encontrados por Carvalho et al. (2009) e Miranda (2008) que, ao analisar amostras de capim-marandu obtidas via pastejo simulado no período da seca, obtiveram médias de 5,49 e 6,11\% de PB, respectivamente. Os valores de PB situaramse abaixo do mínimo necessário (7\%) para garantir adequada fermentação dos carboidratos estruturais no rúmen (Minson, 1990), o que caracteriza a forragem como de baixa qualidade e salienta a necessidade da suplementação com PB.

O teor médio de FDN para forragem foi de 75,1\%, superior aos valores encontrados por Euclides et al. (2009), de 70,1\%, em amostras de lâminas foliares, e próximas ao valor encontrado por Carvalho et al. (2009) de 75,28\%.

O SE, composto apenas por ingredientes energéticos (milho grão moído) e fontes de minerais (mistura mineral e cloreto de sódio), tem valores baixos de

Tabela 3. Teores médios de massa de matéria seca, matéria orgânica, proteína bruta, fibra em detergente neutro, fibra em detergente ácido, hemicelulose e matéria mineral de amostras de capim-marandu obtidas via simulação manual de pastejo, em cada período experimental.

\begin{tabular}{lccrr}
\hline Item & Agosto & Setembro & Outubro & Média \\
\hline Matéria seca (\%) & 39,10 & 69,63 & 88,07 & 65,60 \\
Matéria orgânica $^{(1)}$ & 91,06 & 90,78 & 91,14 & 90,99 \\
Proteína bruta $^{(1)}$ & 8,01 & 3,32 & 3,01 & 4,78 \\
Fibra em detergente neutro $^{(1)}$ & 67,25 & 75,36 & 82,69 & 75,10 \\
Fibra em detergente ácido $^{(1)}$ & 28,62 & 37,26 & 46,05 & 37,31 \\
Hemicelulose $^{(1)}$ & 38,64 & 38,10 & 36,64 & 37,79 \\
Matéria mineral $^{(1)}$ & 8,94 & 9,22 & 8,86 & 9,01 \\
\hline (1)Expresso em percentagem da massa de matéria seca
\end{tabular}

${ }^{(1)}$ Expresso em percentagem da massa de matéria seca. proteína $(5,57 \%)$ e sua função é fornecer energia e minerais ao animal. Já o SM, formulado com fontes proteicas, energéticas e de minerais, tem a função de fornecer simultaneamente energia, proteína e minerais, para melhorar a sincronia entre a liberação ruminal de $\mathrm{N}-\mathrm{NH}_{3}$ e energia; nesse suplemento, o teor de PB é de $18,74 \%$. O SP foi formulado com fontes proteicas e minerais $(38,69 \%$ de $\mathrm{PB})$, a fim de fornecer alta quantidade de proteína, em virtude da baixa disponibilidade desse nutriente nas gramíneas tropicais no período da seca (Tabela 4).

Com base no consumo de suplemento dos tratamentos (Tabela 5), os suplementos MM, SE, SM e SP formulados forneceram 0, 4,47, 14,40 e 35,01 g por animal por dia de PB. Portanto, as exigências dos animais foram completadas pela ingestão de forragem, o que pode ter sido estimulado pelo consumo de suplemento em razão de um possível efeito aditivo causado pelo uso do suplemento como catalisador da degradação da forragem no rúmen.

Miranda (2008), ao trabalhar com borregas suplementadas a pasto com peso médio de $28 \mathrm{~kg}$, encontrou diferença para o desempenho dos animais: o maior desempenho foi atribuído à diferença no consumo de massa de matéria seca total, que foi maior para os tratamentos suplementados em comparação ao tratamento testemunha (mistura mineral). O autor também encontrou diferença para o consumo de massa de matéria seca de forragem, que foi menor para o fornecimento de $1 \%$ do PC dos animais em comparação aos suplementos fornecidos a $0,5 \%$ do PC. No presente trabalho, o consumo de massa de matéria seca de forragem não diferiu do tratamento

Tabela 4. Teores médios de massa de matéria seca, matéria orgânica, proteína bruta, fibra em detergente neutro, fibra em detergente ácido, hemicelulose e matéria mineral de amostras de suplementos e ingredientes, com base na massa de matéria seca.

\begin{tabular}{|c|c|c|c|c|c|}
\hline \multirow[t]{2}{*}{ Item } & \multicolumn{3}{|c|}{ Suplemento $^{(2)}$} & \multicolumn{2}{|c|}{ Ingrediente } \\
\hline & SE & SM & SP & Milho & Farelo de soja \\
\hline Matéria seca (\%) & 94,08 & 94,35 & 92,12 & 88,04 & 87,39 \\
\hline Matéria orgânica ${ }^{(1)}$ & 57,38 & 68,30 & 51,74 & - & 93,15 \\
\hline Proteína bruta ${ }^{(1)}$ & 5,57 & 18,74 & 38,69 & 8,44 & 46,78 \\
\hline Fibra em detergente neutro ${ }^{(1)}$ & 11,02 & 17,66 & 24,68 & 19,77 & 34,68 \\
\hline Fibra em detergente ácido ${ }^{(1)}$ & 1,62 & 2,40 & 4,81 & 3,12 & 8,95 \\
\hline Hemicelulose $^{(1)}$ & 15,45 & 15,25 & 19,87 & 16,65 & 25,73 \\
\hline Matéria mineral $^{(1)}$ & 42,62 & 31,70 & 48,26 & - & 6,85 \\
\hline
\end{tabular}


testemunha (mistura mineral), o que não caracteriza o efeito aditivo, e não houve substituição do consumo de forragem em função da ingestão de suplementos. Assim, o maior desempenho encontrado para os animais que consumiram os suplementos SM e SP na faixa de $0,4 \%$ do PC, em sistema de autocontrole de consumo, pode ser atribuído a um maior consumo de MST e de PB em grama por animal por dia, em comparação aos animais que receberam os suplementos MM e SE.

O menor desempenho encontrado para o tratamento SE em comparação ao MM pode ser explicado pela competição das bactérias ruminais por nutrientes, principalmente o $\mathrm{N}$, que é escasso nas forragens no período da seca. Essa redução nas quantidades de $\mathrm{N}-\mathrm{NH}_{3}$, com o uso de suplementos energéticos, também é citada por Paulino et al. (2007) como efeito da competição de microrganismos que degradam carboidratos não fibrosos (amido), fornecidos via $\mathrm{SE}$, que competem pelo $\mathrm{N}-\mathrm{NH}_{3}$ ruminal, em baixa disponibilidade nas forragens de baixa qualidade, o que diminui ainda mais a oferta de $\mathrm{N}^{-\mathrm{NH}_{3}}$ para os microrganismos que degradam carboidratos fibrosos. Isso gera um efeito chamado repressão catabólica ou efeito carboidrato. De acordo com os autores, este efeito prejudica a degradação da fibra em detergente neutro potencialmente digestível (FDNpd), com possíveis efeitos sobre o consumo de forragem.

A capacidade do consumo de forragem pelos animais ruminantes é afetada pela dinâmica de desaparecimento e pela passagem da FDNpd e da fibra em detergente neutro indigestível (FDNi) no rúmen, pois as referidas frações exercem efeito de repleção ruminal. Entretanto, à medida que a FDNpd é degradada, a proporção da FDNi em relação à FDNpd aumenta. A densidade da

Tabela 5. Peso corporal inicial e final, ganho de peso total, ganho médio diário e consumo de suplemento pelos ovinos mantidos em pastos de capim-marandu, em função dos diferentes suplementos ${ }^{(1)}$.

\begin{tabular}{lcccc}
\hline Variável & \multicolumn{4}{c}{ Suplemento $^{(2)}$} \\
\cline { 2 - 5 } & MM & SE & SM & SP \\
\hline Peso corporal inicial (kg) & 22,77 & 25,03 & 22,36 & 26,31 \\
Peso corporal final (kg) & 24,58 & 24,36 & 24,39 & 32,75 \\
Ganho de peso total (kg) & $1,448 \mathrm{c}$ & $-0,672 \mathrm{~d}$ & $2,026 \mathrm{~b}$ & $6,44 \mathrm{a}$ \\
Ganho médio diário (kg) & $0,017 \mathrm{c}$ & $-0,008 \mathrm{~d}$ & $0,024 \mathrm{~b}$ & $0,077 \mathrm{a}$ \\
Ganho diferencial em relação ao sal mineral & - & $-0,025$ & 0,007 & 0,060 \\
Consumo de suplemento (g por dia) & 8,30 & 85,40 & 81,41 & 98,25 \\
\hline (1) Médias seguidas de letras iguais, nas linhas, não diferem entre si pelo teste $^{\prime}$ & & & &
\end{tabular}

partícula também aumenta, o que leva esta partícula para estratos mais ventrais do rúmen e, portanto, mais próximos da zona de escape ruminal (Vieira et al., 2008a, 2008b). Quanto mais rápido for o processo de degradação ruminal da FDNpd (taxa de degradação), mais rápida será a saída do resíduo não digerido do rúmen (FDNi), o que libera espaço para que o animal possa consumir mais alimento. Assim, o uso de suplemento com a finalidade de aumentar a taxa de degradação ruminal da FDNpd pode alterar o consumo de forragem por ovinos em pastejo, o que parece ter ocorrido com o uso do SP. Isso demonstra a expressão do efeito aditivo da suplementação proteica, que tem como resposta o aumento do ganho de peso.

$\mathrm{Na}$ formulação dos suplementos (Tabela 2), foram usados $30 \%$ de mistura mineral e $10 \%$ de sal comum $(\mathrm{NaCl})$, com o objetivo de regular e aumentar a frequência com que os animais consumiam o suplemento. O consumo de suplemento ficou abaixo da quantidade fornecida de $0,105 \mathrm{~kg}$ por animal por dia (Tabela 5), o que demonstra que as quantidades de mistura mineral e sal comum utilizadas foram capazes de regular o consumo de suplemento na faixa de $0,4 \%$ de PC dos animais.

A concentração de amônia no líquido ruminal para os animais que receberam o SE, em ambos os tempos de coleta, foram inferiores as dos animais que receberam a MM (Tabela 6). Comportamento semelhante foi observado por Zervoudakis et al. (2010), que destacaram que este tipo de suplemento, associado ao inadequado suprimento de PDR, induz às baixas concentrações de amônia no rúmen, tendo como consequência a redução do crescimento da microbiota ruminal e, com isso, a digestão da fibra da forragem. A digestão mais lenta da fibra no rúmen poderia retardar a taxa de passagem da digestão do rúmen, o que afeta de forma negativa o consumo e o desempenho animal.

A concentração de amônia variou entre os suplementos e no tempo após a coleta. Observouse relação direta entre a percentagem de $\mathrm{PB}$ dos suplementos e o padrão de liberação de amônia $\left(\mathrm{N}-\mathrm{NH}_{3}\right)$ no rúmen, em virtude de os suplementos com maiores teores de proteína fornecerem maior quantidade de nitrogênio às bactérias (Tabela 6).

A concentração de $\mathrm{N}_{-} \mathrm{NH}_{3}$ no tempo zero foi maior que no tempo quatro horas no tratamento SP. Esta maior concentração pode ser explicada pelo fato de o suplemento usado ser de autocontrole do consumo, ou 
seja, o suplemento está presente durante 24 horas no cocho, e o seu consumo é regulado em quantidade e frequência pelo próprio animal.

Miranda (2008), em ovinos suplementados em pastagem de $U$. brizantha cv. Marandu, testou níveis de suplementação e de $\mathrm{PB}$ em suplementos múltiplos no período da seca e encontrou concentração de $\mathrm{N}-\mathrm{NH}_{3}$ de $18,06 \mathrm{mg} \mathrm{dL}^{-1}$ para o tratamento $25 \%$ de $\mathrm{PB}$, fornecido a $0,5 \%$ do PC dos animais, resultado semelhante ao obtido neste trabalho para o tratamento SM. O autor encontrou ainda concentração de $\mathrm{N}_{-} \mathrm{NH}_{3}$ de $22,45 \mathrm{mg}$ $\mathrm{dL}^{-1}$ para o tratamento $25 \%$ de $\mathrm{PB}$ fornecido a $1,0 \%$ do PC dos animais, valor próximo ao encontrado neste trabalho para o tratamento SP.

Em todos os suplementos, as concentrações de amônia ruminal se mantiveram em concentrações acima de $5 \mathrm{mg} \mathrm{dL}^{-1}$, considerada por Sampaio et al. (2010) como adequada para manter a atividade microbiana no rúmen de ruminantes alimentados com forrageiras tropicais de baixa qualidade. Os autores verificaram que, para maximizar o consumo de forrageiras de baixa qualidade, é necessário manter $10 \mathrm{mg} \mathrm{dL}^{-1}$ de amônia. A concentração de $\mathrm{N}^{-\mathrm{NH}_{3}}$ no SP, nos tempos zero e quatro horas, e no tratamento SM, no tempo quatro horas, foi superior à de $20 \mathrm{mg} \mathrm{dL}^{-1}$ recomendada por Leng (1990), que seria ideal para maximização do consumo voluntário em condições tropicais.

As concentrações de $\mathrm{N}^{-N_{H}}$ de 8,38 e $7,36 \mathrm{mg} \mathrm{dL}^{-1}$ para os tempos zero e quatro horas para o SE foram inferiores aos outros tratamentos. Este resultado pode ser justificado com base nos estudos feitos por Souza et al. (2010), em que a redução nas concentrações de amônia ruminal está diretamente relacionada ao fornecimento de fontes energéticas (fornecimento de

Tabela 6. Concentração $\left(\mathrm{mg} \mathrm{dL}^{-1}\right)$ de nitrogênio amoniacal $\left(\mathrm{N}-\mathrm{NH}_{3}\right)$ e $\mathrm{pH}$ ruminal nos tempos zero e quatro horas, de ovinos mantidos em pastos de capim-marandu, em função dos diferentes suplementos ${ }^{(1)}$.

\begin{tabular}{|c|c|c|c|c|c|c|}
\hline \multirow[t]{2}{*}{ Variável } & \multirow{2}{*}{$\begin{array}{l}\text { Tempo } \\
(\mathrm{h})^{(2)}\end{array}$} & \multicolumn{4}{|c|}{ Suplemento $^{(3)}$} & \multirow{2}{*}{$\begin{array}{l}\mathrm{CV} \\
(\%)\end{array}$} \\
\hline & & MM & SE & SM & SP & \\
\hline $\mathrm{N}-\mathrm{NH}_{3}$ & zero & $8,97 b$ & $8,38 \mathrm{c}$ & $14,22 b$ & $29,31 \mathrm{a}$ & 59,67 \\
\hline $\mathrm{N}-\mathrm{NH}_{3}$ & quatro & $10,57 b$ & $7,36 \mathrm{c}$ & $21,58 \mathrm{a}$ & $24,50 \mathrm{a}$ & 31,39 \\
\hline $\mathrm{pH}$ & zero & $6,27 \mathrm{a}$ & $6,38 \mathrm{a}$ & $6,28 \mathrm{a}$ & $6,31 \mathrm{a}$ & 2,41 \\
\hline $\mathrm{pH}$ & quatro & $6,30 \mathrm{a}$ & $6,40 \mathrm{a}$ & $6,18 \mathrm{a}$ & $6,24 a$ & 2,14 \\
\hline
\end{tabular}

${ }^{(1)}$ Médias seguidas de letras iguais, nas linhas, não diferem entre si pelo teste Student-Newman-Keulls, a 5\% de probabilidade. ${ }^{(2)}$ Tempos zero e quatro horas: antes e quatro horas após o fornecimento do suplemento. ${ }^{(3)} \mathrm{MM}$, mistura mineral; SE, suplemento energético; SM, suplemento mineral; SP, suplemento proteico. milho). Conforme os autores, as bactérias que degradam celulose requerem amônia para o seu crescimento, e baixas concentrações de amônia podem limitar a atividade microbiana e reduzir a taxa e a extensão de degradação da fibra. Por isso, a amônia ruminal é um fator limitante na utilização da forragem, o que ressalta a importância de se considerar as diferentes fontes proteicas na formulação de suplementos.

Não foram encontradas diferenças significativas ( $p>0,05)$ para os valores de $\mathrm{pH}$ para os suplementos e os tempos avaliados, o que contraria o pressuposto de que o fornecimento de suplementos ricos em amido altera o pH ruminal (Mould et al., 1983). Todos os valores de $\mathrm{pH}$ foram superiores ao de 6,20 citado por Hoover (1986) como o limite para a atividade de microrganismos fibrolíticos.

Estudos conduzidos no Brasil indicam que níveis elevados de fornecimento de suplementos para animais em pastejo não são capazes de causar distúrbios severos ao ambiente ruminal quanto ao $\mathrm{pH}$ (Detmann et al., 2005). Segundo Paulino et al. (2007), este efeito pode ser atribuído à alta efetividade da fibra de gramíneas tropicais em pastejo.

Os suplementos que apresentaram os maiores custos por megagrama de produto também foram os que tiveram melhor resultado econômico, com maior margem bruta (Tabela 7). A margem bruta para a MM foi maior que para o SM, apesar de seu desempenho ter sido maior. Esta maior margem bruta pode ser explicada pelo baixo consumo da MM, em comparação aos outros suplementos avaliados, mesmo com valor por quilograma de produto ( $\mathrm{R} \$ 1,88)$ superior. Embora o SM tenha alcançado desempenho produtivo superior $(0,024 \mathrm{~g}$ por animal por dia), a MM $(0,017 \mathrm{~g}$ por animal por dia) obteve margem bruta menor, resultado

Tabela 7. Avaliação econômica de produção de ovinos mantidos em pastos de capim-marandu, em função dos diferentes suplementos.

\begin{tabular}{|c|c|c|c|c|}
\hline \multirow[t]{2}{*}{ Indicador econômico } & \multicolumn{4}{|c|}{ Suplemento ${ }^{(2)}$} \\
\hline & MM & SE & SM & SP \\
\hline Custo suplemento ( $\mathrm{R} \$$ por $\mathrm{Mg}$ ) & $1.875,00$ & 882,50 & 961,50 & $1.038,50$ \\
\hline Custo por dia com suplemento ( $\mathrm{R} \$$ ) & 0,02 & 0,08 & 0,08 & 0,10 \\
\hline Custo por dia com mão de obra (R\$) & 0,036 & 0,036 & 0,036 & 0,036 \\
\hline Custo diário $(\mathrm{R} \$)$ & 0,052 & 0,111 & 0,114 & 0,138 \\
\hline Custo do ganho ( $\mathrm{R} \$$ por $\mathrm{kg}$ ) & 3,03 & $-13,92$ & 4,76 & 1,79 \\
\hline Margem bruta por kg de ganho ${ }^{(1)}$ & 2,58 & $-5,92$ & 0,24 & 2,17 \\
\hline
\end{tabular}

${ }^{(1)}$ Valor considerado para venda do quilograma de peso corporal, R\$ 3,50.

${ }^{(2)}$ MM, mistura mineral; SE, suplemento energético; SM, suplemento mineral; SP, suplemento proteico. 
da interação negativa entre o maior custo diário e o baixo ganho de peso diferencial em relação à mistura mineral de $0,007 \mathrm{~g}$ por animal por dia.

A margem bruta para o SE foi a menor e resultou em desempenho econômico negativo de $-10,42$ reais, o que pode ser explicado pela combinação entre o maior consumo de suplemento em comparação à $\mathrm{MM}$ e ao menor desempenho em comparação à qualquer um dos outros suplementos avaliados. Miranda (2008) e Ribeiro (2008) encontraram margem bruta superior para os suplementos, em comparação à MM, o que demonstra a capacidade da suplementação em aumentar a eficiência econômica da criação de ovinos em pastejo.

A maior margem bruta para o SP é função do alto ganho de peso para este suplemento, que apresenta ganho diferencial em relação aos outros de 0,060 , 0,085 e $0,053 \mathrm{~g}$ por animal por dia, respectivamente, para os suplementos mistura mineral, energético e múltiplo. O SP proporcionou a terminação dos animais em menor tempo, o que libera áreas da propriedade para novos lotes de animais ou para outras atividades agropecuárias, assim como um giro de capital mais rápido. O SP, apesar de ser o mais oneroso, proporciona a menor idade de abate dos animais, o que aumenta a eficiência do sistema de produção. $\mathrm{O}$ uso do SE proporciona a maior idade ao abate entre os suplementos utilizados, em virtude da diminuição do ganho de peso mesmo com o suplemento MM.

\section{Conclusões}

1. O uso de suplementos proteicos propicia melhor desempenho, bem como maior margem bruta por quilograma de ganho dos animais em comparação ao suplemento múltiplo e à mistura mineral, para ovinos mantidos em pastos de capim-marandu de baixa qualidade.

2. $\mathrm{O}$ fornecimento de suplemento energético à base de amido prejudica o desempenho de ovinos mantidos em pastos de capim-marandu de baixa qualidade.

3. A adição de $30 \%$ de mistura mineral e $10 \%$ de $\mathrm{NaCl}$ nos suplementos é capaz de regular o consumo de suplemento pelos animais em torno de $0,4 \%$ do peso corporal de ovinos mantidos em pastos de capim-marandu de baixa qualidade.

4. O uso de suplementos energéticos a $0,4 \%$ do peso corporal não prejudica o $\mathrm{pH}$ ruminal de ovinos mantidos em pastos de capim-marandu de baixa qualidade.

\section{Referências}

CARVALHO, D.M.G.; ZERVOUDAKIS, J.T.; CABAL, L.S.; PAULA, N.F.; MORAES, E.H.B.K.; OLIVEIRA, A.A.; KOSCHECK, J.F.W. Fontes de energia em suplementos múltiplos para recria de bovinos em pastejo no período da seca: desempenho e análise econômica. Revista Brasileira de Saúde e Produção Animal, v.10, p.760-773, 2009.

CAVALCANTI FILHO, L.F.M.; SANTOS, M.V.F.; FERREIRA, M.A.; LIRA, M.A.; FARIAS, I.; FERREIRA, R.L.C.; LUCENA, J.E.C. Desempenho de novilhas em pastagem de Brachiaria decumbens após período de suplementação. PesquisaAgropecuária Brasileira, v.39, p.1247-1252, 2004.

COSTA, V.A.C.; DETMANN, E.; VALADARES FILHO, S.C.; PAULINO, M.F.; HENRIQUES, L.T.; MANTOVANI, H.C. Degradação in vitro da fibra em detergente neutro de forragem tropical de baixa qualidade em função de suplementação com proteína e/ou carboidratos. Revista Brasileira de Zootecnia, v.37, p.494-503, 2008.

DETMANN, E.; PAULINO, M.F.; VALADARES FILHO, S.C.; CECON, P.R.; ZERVOUDAKIS, J.T.; CABRAL, L.S.; GONÇALVES, L.C.; VALADARES, R.F.D. Níveis de proteína em suplementos para terminação de bovinos em pastejo durante o período de transição seca/águas: digestibilidade aparente e parâmetros do metabolismo ruminal e dos compostos nitrogenados. Revista Brasileira de Zootecnia, v.34, p.1380-1391, 2005.

EUCLIDES, V.P.B.; CARDOSO, E.G.; MACEDO, M.C.M.; OLIVEIRA, M.P. de. Consumo voluntário de Brachiaria decumbens cv. Basilisk e Brachiaria brizantha cv. Marandu sob pastejo. Revista Brasileira de Zootecnia, v.29, p.2200-2208, 2000.

EUCLIDES, V.B.P.; MACEDO, M.C.M.; VALLE, C.B.; DIFANTE, G.S.; BARBOSA, R.A.; CACERE, E.R. Valor nutritivo da forragem e produção animal em pastagens de Brachiaria brizantha. Pesquisa Agropecuária Brasileira, v.44, p.98-106, 2009.

GOMES JÚNIOR, P.; PAULINO, M.F.; DETMANN, E.; VALADARES FILHO, S.C.; ZERVOUDAKIS, J.T.; LANA, R.P. Desempenho de novilhos mestiços na fase de crescimento suplementados durante a época seca. Revista Brasileira de Zootecnia, v.31, p.139-147, 2002.

HOOVER, W.H. Chemical factors involved in ruminal fiber digestion. Journal of Dairy Science, v.69, p.2755-2766, 1986.

LENG, R.A. Factors affecting the utilization of "poor-quality" forages by ruminants particularly under tropical conditions. Nutrition Research Review, v.3, p.277-303, 1990.

MALLMANN, G.M.; PATINO, H.O.; SILVEIRA, A.L.F.; MEDEIROS, F.S.; KNORR, M. Consumo e digestibilidade de feno de baixa qualidade suplementado com nitrogênio não protéico em bovinos. Pesquisa Agropecuária Brasileira, v.41, p.331-337, 2006.

MINSON, D.J. Forage in ruminant nutrition. Queensland: Academic, 1990. 483p.

MIRANDA, L. Suplementação de ovinos em pastagem de Brachiaria brizantha cv. Marandu durante a época seca: desempenho, comportamento e parâmetros ruminais. 2008. 89p. 
Dissertação (Mestrado) - Universidade Federal de Mato Grosso, Cuiabá.

MORAES, E.H.B.; PAULINO, M.F.; VALADARES FILHO, S.C.; MORAES, K.A.K.; DETMANN, E.; SOUZA, M.G. Avaliação nutricional de estratégias de suplementação para bovinos de corte durante a estação da seca. Revista Brasileira de Zootecnia, v.39, p.608-616, 2010.

MOULD, F.L.; ORSKOV, E.R.; MANN, S.O. Associative effects of mixed feeds. I. Effects of type and level of supplementation and the influence of the rumen fluid $\mathrm{pH}$ on cellulolysis in vivo and dry matter digestion of various roughages. Animal Feed Science and Technology, v.10, p.15-30, 1983.

PAULINO, M.F.; DETMANN, E.; VALADARES FILHO, S.C. Suplementação animal em pasto: energética ou protéica? In: SIMPÓSIO SOBRE MANEJO ESTRATÉGICO DA PASTAGEM, 3., 2006, Viçosa. Anais. Viçosa: UFV, 2006. p.359-392.

PAULINO, M.F.; DETMANN, E.; VALADARES FILHO, S.C.; LANA, R.P. Soja grão e caroço de algodão em suplementos múltiplos para terminação de bovinos mestiços em Pastejo. Revista Brasileira de Zootecnia, v.31, p.484-491, 2002. Suplemento.

RIBEIRO, P.P.O. Níveis de proteína em suplementos múltiplos para ovinos manejados em pastagem de Panicum maximum Jaqc cv. Aruana na época seca. 2008. 60p. Dissertação (Mestrado) - Universidade Federal de Mato Grosso, Cuiabá.

SAEG: sistema de análises estatísticas e genéticas. Viçosa: UFV, 1995.

SAMPAIO, C.B.; DETMANN, E.; PAULINO, M.F.; VALADARES FILHO, S.C.; SOUZA, M.A.; LAZZARINI, I.; PAULINO, P.V.R.; QUEIROZ, A.C. Intake and digestibility in cattle fed low-quality tropical forage and supplemented with nitrogenous compounds. Tropical Animal Health and Production, v.42, p.1471-1479, 2010.

SILVA, D.J.; QUEIROZ, A.C. Análise de alimentos: métodos químicos e biológicos. 3.ed. Viçosa: UFV, 2002. 165p.

SILVA, F.F.; SÁ, J.F.; SCHIO, A.R.; ÍTAVO, L.C.V.; SILVA, R.R.; MATEUS, R.G. Suplementação a pasto: disponibilidade e qualidade x níveis de suplementação x desempenho. Revista Brasileira de Zootecnia, v.38, p.371-389, 2009. Suplemento.

SOUZA, M.A.; DETMANN, E.; PAULINO, M.F.; SAMPAIO, C.B.; LAZZARINI, I.; VALADARES FILHO, S.C. Intake, digestibility and rumen dynamics of neutral detergent fibre in cattle fed low-quality tropical forage and supplemented with nitrogen and/or starch. Tropical Animal Health and Production, v.42, p.1299-1310, 2010.

VAN SOEST, P.J. Nutritional ecology of the ruminant. $2^{\text {nd }}$ ed. Ithaca: Cornell University,1994.

VIEIRA, R.A.M.; TEDESCHI, L.O.; CANNAS, A. A generalized compartmental model to estimate the fibre mass in the ruminoreticulum: 1. Estimating parameters of digestion. Journal of Theoretical Biology, v.255, p.345-356, 2008a.

VIEIRA, R.A.M.; TEDESCHI, L.O.; CANNAS, A. A generalized compartmental model to estimate the fibre mass in the ruminoreticulum: 2. Integrating digestion and passage. Journal of Theoretical Biology, v.255, p.357-368, 2008b.

ZERVOUDAKIS, J.T.; PAULINO, M.F.; CABRAL, L.S.; DETMANN, E.; VALADARES FILHO, S.C.; MORAES, E.H.B.K. Parâmetros nutricionais de novilhos sob suplementação em sistema de autocontrole de consumo no período de transição águas-seca. Revista Brasileira de Zootecnia, v.39, p.2753-2762, 2010.

Recebido em 30 de agosto de 2010 e aprovado em 21 de janeiro de 2011 